\title{
A RELAÇÃO TRANSFERENCIAL COM CRIANÇAS AUTISTAS: UMA CONTRIBUIÇÃO A PARTIR DO REFERENCIAL DE WINNICOTT
}

\author{
Livia Milhomem Januário* \\ Maria Izabel Tafuri**
}

\section{Resumo}

$\mathrm{O}$ artigo reflete a relação transferencial na clínica psicanalítica com crianças autistas. Verifica-se que, a partir do trabalho de Melanie Klein (1930), a análise da transferência com crianças autistas é realizada por meio de interpretações verbais e o lugar do analista é o de intérprete. A partir do pensamento de Winnicott, o analista ganha outro lugar na situação transferencial com a criança autista para além da função de intérprete. Dentre as ideias de Winnicott, enfatiza-se a questão do holding e da interpretação, o modelo da "mãe suficientemente boa" como um norteador da transferência e a importância dos vínculos sensoriais não-verbais na relação transferencial.

Palavras-chave: transferência, interpretação, holding, autismo.

\begin{abstract}
Transferential RELATION WITH AUTISTIC CHILDREN: A CONTRIBUTION FROM WINNICOTT'S APPROACH

This article reflects about the transferential relation in the psychoanalytic clinic with autistic children. It is verified that, from the work of Melanie Klein (1930), the analysis of transference with autistic children is carried out through verbal interpretations and the place of the analyst is that of an interpreter. From the thought of Winnicott, the analyst gains ano-
\end{abstract}

* Mestra e doutoranda em Psicologia Clínica e Cultura na Universidade de Brasília (UnB); Pesquisadora do Laboratório de Psicopatologia e Psicanálise do Instituto de Psicologia da UnB.

** Doutora em psicologia clínica; Professora Adjunta de psicologia clínica na Universidade de Brasília (UnB); Coordenadora do Laboratório de Psicopatologia e Psicanálise do Instituto de Psicologia da UnB. 
ther place in the transferential situation with the autistic child, far beyond the function of an interpreter. Winnicott emphasizes the ideas of holding, interpretation, and the model of a "good enough mother" as a guide for the transference and the importance of non-verbal sensory links in the transferential relation.

Keywords: transference, interpretation, holding, autism.

\section{O SURGIMENTO DA CLÍNICA PSICANALÍTICA COM CRIANÇAS AUTISTAS}

Com Melanie Klein ([1930] 1996) surge, pela primeira vez, no contexto psicanalítico, a descrição do tratamento bem-sucedido de uma criança ensimesmada de apenas quatro anos de vida, o Pequeno Dick. Apesar de Freud não acreditar na análise de pacientes isolados afetivamente, Klein apresenta a possibilidade de analisá-los por meio do método clássico freudiano, a interpretação.

Klein difunde a psicanálise com crianças autistas ao descrever o caso do pequeno Dick. Em nota explicativa, a comissão editorial inglesa afirma que o material clínico apresentado com o caso Dick "inaugura uma nova era. Em termos históricos, esse é o primeiro relato publicado da análise de uma criança psicótica, onde fica claro que é possível estabelecer um contato analítico e despertar o desenvolvimento" (Klein, [1930] 1996: 249).

Nesse caso, Klein descreve a história clínica de uma criança ensimesmada com sintomatologia parecida com a de crianças ditas esquizofrênicas, no entanto com ausência de vida fantasiosa. Assim, fenomenologicamente, a descrição que Klein faz dessa criança acaba sendo muito semelhante à síndrome descrita por Kanner ([1943] 1997) como "autismo infantil precoce".

Na clínica com Dick, Klein ([1930] 1996) se depara com uma questão técnica: seria possível interpretar uma criança que não estabelece, a princípio, uma relação transferencial? A técnica do brincar e da interpretação do jogo desenvolvida por ela acompanha as representaçoos simbólicas da criança e dá acesso à sua ansiedade e ao seu sentimento de culpa por meio do simbolismo revelado no brincar da criança. Porém Dick não estabelece uma relação afetiva e simbólica com os objetos, "suas ações fortuitas diante deles não eram tingidas pela fantasia e, por isso, não era possível atribuir-lhes o caráter de representações simbólicas" (Klein, [1930] 1996: 256-257). Klein conclui então que na análise se "viu obrigada a partir desse ponto (ausência de uma relação simbólica com as coisas), que era o obstáculo fundamental para se estabelecer contato com o menino" (Klein, [1930] 1996: 256-257; grifo da autora).

Entretanto, aqui há uma questão de fundamental importância para o saber 
psicanalítico acerca da psicanálise com crianças. Por que a psicanalista teria insistido em continuar utilizando a técnica da interpretação do jogo com Dick, uma criança que não apresenta pensamentos fantasiosos e que não representa a realidade? Para que antecipar um jogo para a criança a partir do pensamento do próprio analista? Nas palavras da autora:

Em geral, não interpreto o material até ele ter sido expresso em várias representaçôes. Contudo, num caso em que a capacidade de representação era quase inexistente, fui obrigada a basear minhas interpretaçôes no meu conhecimento geral, pois as representações que se manifestavam no comportamento de Dick eram relativamente vagas (Klein, [1930] 1996: 260).

Klein afirma que na análise do Dick conseguiu "ter acesso ao inconsciente do menino ao entrar em contato com os rudimentos de fantasia e formação de símbolos que ele apresentava” (Klein, [1930] 1996: 259). Com essa passagem, observa-se que Klein não altera sua técnica de trabalho ao atender crianças ensimesmadas. Ela continua interpretando o brincar da criança tendo como referência o sadismo e o complexo de Édipo, ou seja, ela interpreta os comportamentos de Dick com base nos símbolos primordiais como o seio e o pênis, visando à diminuição da ansiedade e do sentimento de culpa. Percebe-se, assim, que a autora interpreta a partir do conhecimento prévio da teoria psicanalítica e do saber do analista. Klein utiliza então as interpretações verbais para analisar a relação analítica e encontrar sentido e valor simbólico nos comportamentos da criança, não realizando uma mudança significativa na técnica psicanalítica clássica utilizada com crianças ditas neuróticas.

Muitos autores como, por exemplo, Figueiredo (2000) criticam essa postura de Klein, afirmando que sua técnica tende a incrementar a intrusividade do analista: suas "interpretações precoces, tendenciosas, unilateralmente centradas nos vínculos transferenciais e a imposição impaciente destes vínculos tendem a fazer do campo transferencial-contratransferencial um campo excessivamente fechado" (Figueiredo, 2000: 27).

Ao analisar o trabalho de Klein, Tafuri (2003) conclui que o lugar que Klein ocupa na clínica psicanalítica com a criança autista é o lugar de analista intérprete. O papel da analista é o de interpretar, o mais breve possível, o simbolismo revelado por detalhes do comportamento da criança, mesmo na ausência da fala e do brincar simbólico. Ao questionar os princípios teóricos e técnicos da clínica psicanalítica com crianças autistas, a autora ressalta que o lugar de analista intérprete das ansiedades mal simbolizadas fica reconhecido no âmbito psicanalítico como o da "verdadeira psicanálise" e que isso marca bastante o desenvolvimento posterior da 
clínica psicanalítica com crianças.

Tafuri (2003) explica ainda que a clínica psicanalítica com crianças autistas foi "tradicionalmente desenvolvida a partir de um eixo básico: atribuir sentido ou valor significante e interpretar os comportamentos gestuais e sonoros do infans" (Tafuri, 2003: 169). Essa maneira de trabalhar produziu diferentes formas de interpretação: "interpretação do jogo (Klein), interpretação de figuras e objetos autísticos (Tustin, Meltzer, Haag e Ogden) e interpretação ou tradução dos significantes (Lefort, Dolto, Mannoni, Jerusalinsky e Laznik-Penot)" (Tafuri, 2003: 169), todas tendo como princípio básico a interpretação verbal.

A clínica psicanalítica com crianças obtém com os trabalhos de Winnicott, na década de 1950, uma abertura maior em relação ao setting e ao lugar que o analista ocupa na relação transferencial com a criança. Winnicott é um dos psicanalistas que questiona a função de analista intérprete de símbolos universais que não contemplam a história individual da criança.

$\mathrm{Na}$ concepção winnicottiana, a ênfase recai sobre o manejo clínico, termo utilizado em relação ao cuidado dispensado a determinados pacientes no setting psicanalítico, bem sobre a relação analítica. Abram ([1996] 2000) explica que a graduação do manejo depende da patologia apresentada pelo paciente para que se possa estabelecer o tipo de holding necessário: "com bastante frequência Winnicott faz referência ao holding como uma espécie de manejo" (Abram, [1996] 2000: 139).

\section{A CONCEPÇÃo WINNICOTTIANA: HOLDING E INTERPRETAÇÃO}

Winnicott é um autor que contribui de forma profunda e original para o pensamento psicanalítico. Como Pediatra, inicia seu trabalho com o atendimento dos bebês, dedicando-se ao estudo dos estágios mais primitivos do desenvolvimento emocional do indivíduo. Para o autor, a teoria do desenvolvimento emocional primitivo guia a compreensão dos fenômenos humanos com os quais os analistas se deparam na clínica. Winnicott afirma que os analistas devem ser capazes de localizar o estágio maturacional do indivíduo no qual seu sofrimento teve origem. Desse modo, pode-se compreender a natureza do problema com o qual o sujeito está envolvido, procedendo de forma adequada em relação aos cuidados específicos com o paciente que, por sua vez, devem ser conduzidos de acordo com as necessidades deste.

Diante disso, pode-se observar que Winnicott ([1955a] 2000) costuma dividir os casos clínicos em três categorias distintas com base em diferentes registros de sofrimento decorrentes de diferentes momentos de falhas no processo maturacional 
e que demandam modos distintos e específicos de trabalho clínico.

A primeira variedade clínica refere-se a pacientes ditos neuróticos que funcionam como pessoas inteiras e às dificuldades que se localizam no âmbito dos relacionamentos interpessoais. Nesse caso, a técnica de trabalho é a mesma desenvolvida por Freud. Recorre-se ao setting clássico freudiano, utilizando como ferramenta básica a interpretação da transferência com o intuito de trazer à luz o material inconsciente recalcado (Winnicott, [1955a] 2000).

A segunda é a clínica com pacientes que começaram a se integrar, mas que ainda não conquistaram a estabilidade no seu sentido de unidade. A análise, nesse caso, tem a ver não só com a aquisição de uma unidade como também com a junção do amor e do ódio e o reconhecimento da dependência. O elemento mais importante aqui é a sobrevivência do analista na condição do fator dinâmico. Para Winnicott, a técnica, nesse tipo de trabalho, não difere da primeira categoria, mas surgem novos problemas com relação ao manejo, tendo-se, assim, a junção do manejo aos princípios da análise clássica (Winnicott, [1955a] 2000).

A terceira clínica refere-se ao acolhimento de pacientes psicóticos, no qual a análise precisa lidar com os estágios iniciais do desenvolvimento emocional. Essa clínica relaciona-se com períodos anteriores ao estabelecimento da personalidade como uma entidade. A estrutura pessoal ainda não está integrada e é anterior à aquisição da unidade pessoal em termos de espaço e tempo. Nesse caso, a ênfase recai sobre o manejo clínico e o estabelecimento do setting, caracterizado por uma complexa organização de holding (Winnicott, [1955a] 2000).

Esse terceiro tipo de clínica é o foco deste artigo. Nessa clínica, Winnicott ([1955b] 2000) observa que não é possível considerar o ego uma entidade estabelecida. "Não pode, então, existir também uma neurose de transferência, para a qual certamente é preciso que haja um ego" (Winnicott, [1955b] 2000: 394). O autor afirma que, quando há "um ego intacto e o analista pode ter certeza sobre a qualidade dos cuidados iniciais, o contexto analítico revela-se menos importante que o trabalho interpretativo" (Winnicott, [1955b] 2000: 395). Nesse caso, realizase uma psicanálise clássica, na qual o objetivo do trabalho de análise consiste em trazer para a consciência aquilo que estava inconsciente por meio da interpretação da revivência que ocorre na relação transferencial.

No entanto, na análise de pacientes autistas, eles "não esperam que a análise os torne mais conscientes, mas aos poucos eles podem vir a ter esperança de que lhes seja possível sentir-se reais" (Winnicott, [1988] 1990: 79). Nesse caso, o contexto (setting/ambiente) torna-se mais importante que a interpretação, e a manutenção de uma situação adaptativa ao ego é fundamental.

A clínica com pacientes autistas demanda uma situação analítica que tem 
como característica o que Winnicott denomina de holding. A noção de holding na teoria winnicottiana é de extrema importância para o manejo clínico e o holding é compreendido como sustentação: sustentar determinadas experiências ao longo de um tempo sem interromper a experiência do paciente. Significa oferecer um ambiente/setting que sustente e permita o processo de integração do sujeito.

Em casos extremos, talvez seja necessário que, em algum momento da análise, o holding assuma uma forma física, mas Winnicott ([1954] 2000) relaciona esse cuidado com a compreensão do sofrimento do paciente e a expressão dessa compreensão, de modo que o paciente sinta-se sustentado pelo analista: "toda vez que compreendemos profundamente um paciente, e o mostramos através de uma interpretação correta e feita no momento certo, estamos de fato sustentando o paciente" (Winnicott, [1954] 2000: 354).

Em seus textos, Winnicott revela que, na clínica com pacientes autistas, antes de fornecer interpretaçōes, o objetivo da análise é proporcionar um "ambiente suficientemente bom", que se adapte à necessidade que surge do ser e dos processos de maturação, de modo que se permita o surgimento de um ego, o abandono de organizaçôes defensivas e a retomada do processo de amadurecimento.

Para isso, é necessário que a análise propicie as condições que faltaram nos momentos das falhas ambientais e que impediram o desenvolvimento saudável. Deve-se ainda levar em consideração que cada período do amadurecimento requer condições diferentes, o que leva a modificações no trabalho de análise de acordo com as necessidades de cada paciente em relação a determinado ponto do amadurecimento.

A análise é vista como a satisfação das necessidades com base na noção de holding, o que mostra uma outra forma de trabalho onde, até então, o principal instrumento era a interpretação. Winnicott ([1962] 1983) coloca que, na situação clínica descrita, as interpretações relativas aos conteúdos da sessão produziriam um efeito nocivo quando se considera, por exemplo, a intrusão que uma interpretação transferencial clássica representa ao apresentar o analista como um outro não-eu para um paciente que o necessita, ainda, como fazendo parte de si mesmo. Nesse caso, o analista "teria sido um mau analista fazendo uma boa interpretação" (Winnicott, [1962] 1983: 228).

É importante salientar que na obra de Winnicott a diferenciação entre holding e interpretação não se dá de forma clara. Em alguns de seus textos, como em Holding e interpretação (Winnicott, [1972] 2001), o autor pontua que a interpretação pode funcionar como holding. Desta forma, Winnicott utiliza a noção de ambiente-holding para descrever o setting analítico. Em termos de relação analítica é o setting, a atenção dispensada pelo analista, juntamente com o trabalho inter- 
pretativo, que cria o ambiente de holding que norteia as necessidades psicológicas e físicas do pacientes.

\section{O MODELO DA “MÃE SUFICIENTEMENTE BOA": UM NORTEADOR DA RELAÇÃO TRANSFERENCIAL}

Para Winnicott, a relação transferencial está baseada no paradigma da relação mãe e bebê, no que originalmente eram o lactente e a mãe. A relação analítica assume características fundamentais da relação primitiva mãe-bebê, já que Winnicott relaciona a dependência na transferência à dependência aos estágios do cuidado do lactente e da criança.

Winnicott ([1956] 2000) afirma que a "mãe suficientemente boa" é a mãe que ingressa em estado de "preocupação materna primária”, que, identificada com seu bebê consciente e inconscientemente e em um estado de sensibilidade exacerbada, consegue uma adaptação sensível, ativa e delicada às necessidades do bebê. A "mãe suficientemente boa" também diz respeito à adaptação da mãe às necessidades do bebê, que o torna capaz de ter uma experiência de onipotência que cria a ilusão necessária a um desenvolvimento saudável.

Ao utilizar o modelo da "mãe suficientemente boa" como norteador da transferência, Winnicott ressalta que o analista precisa estar identificado ou mesmo fundido com o paciente, mas também permanecer orientado para a realidade externa. É estar identificado e, ao mesmo tempo, cuidando do paciente, o que só é possível por meio da transicionalidade, ou seja, depende da capacidade do analista de manter o espaço potencial, uma área intermediária que não é inteiramente subjetiva nem objetiva.

Winnicott explica que, nas situações de interrupção precoce no processo de desenvolvimento, o trabalho de análise deve criar um setting em que o paciente possa ter experiências semelhantes à maternagem, mas agora na presença de um ambiente propício ao amadurecimento saudável. Para Winnicott, é por meio das funções maternas de holding, de handling e de "apresentação de objeto", nas fases mais primitivas, que a "mãe suficientemente boa" oferece condiçôes favoráveis para o desenvolvimento dos processos de integração, de personalização e de realização, respectivamente.

Com a função do holding, como visto, a "mãe suficientemente boa" permite o processo de integração, no qual o ego se integra em uma unidade e tem-se o "eu sou" e o início da constituição do si mesmo. Com a função materna de handling (manejo) pode ocorrer a "personalização", isto é, a interação dos aspectos da psique e do soma a partir da qual o bebê adquire a capacidade de habitar o próprio corpo. 
Com a função de "apresentação de objetos", a mãe auxilia o bebê na capacidade de viver a ilusão de onipotência de que o mundo é uma criação sua.

Ainda com relação ao modelo da "mãe suficientemente boa" como norteador da relação transferencial, cabe ressaltar que o analista não é a mãe que cuida de um bebê e não deve utilizar técnicas de maternagem com os pacientes. Apesar de o analista identificar-se na transferência com o paciente e com as suas necessidades primitivas, assim como ocorre com a mãe no estado de "preocupação materna primária", ele precisa manter-se na posição de analista para poder cuidar de forma confiável.

O analista confiável é ou age na transferência como um ambiente facilitador, dirigindo sua atenção para aquilo que o paciente necessita naquele momento. Isso não significa que o analista supre as necessidades do paciente como sua mãe. Caso o analista ultrapasse os cuidados adequados e tente fazer mais do que um analista pode fazer, ele estará sendo o substituto da mãe verdadeira e não um "analista suficientemente bom", assim como a mãe extremamente boa não é uma "mãe suficientemente boa” para o desenvolvimento do bebê. Assim, não se trata também de restaurar experiências, mas de possibilitar condições ambientais para que o amadurecimento emocional do paciente seja retomado.

Winnicott ([1962] 1983) alerta que essa situação clínica não é uma experiência corretiva na transferência, o que seria uma contradição, na medida em que a transferência se dá por meio do processo psicanalítico inconsciente do paciente e depende, para o seu desenvolvimento, da interpretação do analista, que é sempre relativa ao material apresentado pelo paciente. Porém "a prática de uma boa técnica psicanalítica pode por si só ser uma experiência corretiva e, por exemplo, na análise um paciente pode, pela primeira vez na vida, conseguir a atenção total de outra pessoa... ou estar em contato com alguém que é capaz de ser objetivo" (Winnicott, [1962] 1983: 232-233; grifo do autor).

Com relação a essa questão da "mãe suficientemente boa" como norteador da relação transferencial na clínica com pacientes em sofrimento psíquico grave, Safra (2004) ressalta a necessidade de discriminar o que é específico da relação mãe-bebê e o que é específico da condição humana, já que o que se revela nas situações transferenciais não é, necessariamente, a relação mãe-bebê, mas as facetas fundamentais da dimensão humana. Nessa discriminação, a transferência é relacionada aos períodos do desenvolvimento emocional em que o paciente teve maiores dificuldades ou em que apresenta uma falha ambiental precoce e os cuidados maternos são utilizados como metáfora.

Em Holding e interpretação, por exemplo, Winnicott ([1972] 2001) ilustra uma situação clínica na qual o analista é colocado na função transferencial paterna. Nesse caso, em virtude de a história de vida do paciente ser marcada pela ausência 
da figura paterna e pelo não-reconhecimento da maturidade do paciente pelo pai com a proibição do incesto, com a rivalidade e com a impossibilidade de destruir o pai na fantasia, o paciente não pôde fazer uso da figura paterna. Winnicott, ao ocupar o lugar transferencial do pai, pôde facilitar a retomada do processo de constituição desse paciente.

O analista, a partir desse ponto de vista, age de acordo com o lugar em que é colocado pelo paciente no processo transferencial, variando de acordo com as necessidades do paciente e tendo como norteador da transferência não apenas a relação mãe-bebê, mas todo o processo de constituição do sujeito. Winnicott ressalta que o analista só compreende a natureza do sofrimento do sujeito e pode fornecer cuidados específicos de acordo com a necessidade do paciente ao considerar o processo de amadurecimento do indivíduo em sua totalidade. Contudo, o autor alerta que um dos problemas mais difíceis da técnica psicanalítica consiste em saber qual a idade emocional do paciente em um dado momento da relação transferencial.

Winnicott ([1955b] 2000) afirma que quando o analista é suficientemente bom, isto é, está identificado com as necessidades do paciente proporcionando um "ambiente suficientemente bom" em relação à adaptação às necessidades do paciente, este tem a experiência de ser sustentado por um ambiente e esse ambiente (setting/analista) "vai sendo gradualmente percebido pelo paciente como algo que faz nascer a esperança de que o self verdadeiro possa finalmente ser capaz de assumir os riscos que o início da experiência de viver implica" (Winnicott, [1955b] 2000: 486).

\section{OS VÍNCULOS SENSORIAIS NÃO-VERBAIS NA TRANSFERÊNCIA}

Em sua última década de vida, Winnicott ([1968] 1996) desenvolve o estudo do significado da comunicação, afirmando que a habilidade de comunicar-se não está fundada, inicialmente, na aquisição da linguagem, mas, sim, em uma interação não-verbal estabelecida por intermédio da experiência de mutualidade entre mãe e bebê, na qual a mãe está identificada de forma tão intensa com seu bebê que ele se sente compreendido. Consequentemente, a habilidade do bebê de brincar e de simbolizar precede o período em que passa a fazer uso de palavras.

Winnicott ([1968] 1996), ao examinar as experiências iniciais de vida do bebê no que diz respeito à comunicação, afirma que a mãe pode, ou não, falar com seu bebê; isso não é relevante, pois a linguagem não é importante nessa etapa do desenvolvimento emocional. Nessa fase, o importante é a experiência de confiabilidade, que é um tipo de comunicação silenciosa. Dentre as comunicações 
silenciosas iniciais, Winnicott ressalta o movimento que provém da respiração da mãe; o calor de seu hálito; o seu cheiro; o som das batidas de seu coração; a comunicação física que pode ser ilustrada pelo movimento de embalar, no qual a mãe adapta os seus movimentos aos do bebê; e as expressóes do rosto da mãe e o uso que o bebê pode fazer desse rosto. Há também as comunicações não-silenciosas, por meio da melodia, do ritmo e da entonação da voz da mãe, como, por exemplo, a utilização de canções de ninar.

A confiabilidade é extremamente necessária e está intimamente vinculada à integração mãe-bebê em uma unidade, permitindo ao bebê ser e continuar sendo. O mundo do bebê, nos primeiros momentos de vida, se reduz à mãe que deve ser, acima de tudo, confiável. A confiabilidade materna aparece no modo como a mãe cuida do bebê. Para Winnicott, atos de confiabilidade humana estabelecem uma comunicação muito antes que o discurso signifique algo: o modo como a mãe olha quando se dirige à criança, o tom e o som de sua voz, tudo isso é comunicado muito antes que se compreenda o discurso.

A partir da análise da relação mãe-bebê, Winnicott ([1968] 1996: 81) leva o leitor para "um lugar onde a verbalização perde todo e qualquer significado", e ele se questiona: "Que ligação pode haver entre tudo isso e a psicanálise, que se fundamentou no processo de interpretações verbais de pensamentos e ideias verbalizados?”. Em síntese, Winnicott diz que "a psicanálise teve que partir de uma base de verbalização, e que tal método é perfeitamente adequado para o tratamento de um paciente que não seja esquizoide ou psicótico", isto é, para pacientes que não precisam ir em busca de experiências primitivas (Winnicott, [1968] 1996: 81). Esses fenômenos primordiais manifestam-se como características primárias de duas maneiras:

primeiramente, nas fases esquizoides pelas quais qualquer paciente pode passar, ou no tratamento de problemas realmente esquizoides; em segundo lugar, no estudo das experiências iniciais concretas de bebês que estão para nascer, que acabaram de nascer, que são segurados no colo após o nascimento, que receberam cuidados e com os quais nos comunicamos nas primeiras semanas e meses, muito antes da verbalização ter adquirido qualquer significado (Winnicott, [1968] 1996: 82).

Percebe-se, então, que o estudo da relação mãe-bebê revela o que pacientes em fases psicóticas necessitam do analista e há, também, um feedback desses pacientes a partir do qual pode-se aprender a observar as mães e os bebês, vendo mais claramente o que ali se encontra. "Essencialmente, porém, é a partir das mães e dos bebês que aprendemos sobre as necessidades dos pacientes psicóticos, ou de pacientes que 
atravessam fases psicóticas" (Winnicott, [1968] 1996: 90; grifos do autor).

Continuando com esse paralelo entre a relação mãe-bebê e a clínica, Winnicott reflete sobre as implicações para a técnica psicanalítica. Utilizando como exemplo as inflexões que caracterizam o discurso, o autor mostra que o fato de o paciente verbalizar e o analista interpretar não é apenas uma questão de comunicação verbal e que muito depende da maneira como o analista usa as palavras e, portanto, da atitude que se oculta por trás de uma interpretação.

Com relação à clínica psicanalítica com pacientes autistas, o analista é enviado a situações em que as palavras não oferecem o holding necessário, como na relação inicial entre mãe-bebê, na qual a comunicação é estabelecida por meio de vínculos sensoriais não-verbais. Assim, embora a psicanálise se baseie na interpretação verbal, junto ao conteúdo das interpretações e das verbalizações existe algo que tem sua própria importância e se reflete "nas nuanças, no ritmo e em milhares de outras formas que podemos comparar à variedade infinita da poesia" (Winnicott, [1968] 1996: 85).

Furtado (2006) - considerando que, nas etapas primitivas da formação do psiquismo, o universo sensorial desempenha uma função de protagonista da cena psíquica - constata a presença de uma imensa gama de sensações atuantes na relação transferencial, assim como nos momentos primordiais da constituição da subjetividade. Revela que, no trabalho de análise, as experiências sensoriais que fizeram parte da experiência pregressa do analisando moldam a relação transferencial, marcando a forma de apreensão e de ação do sujeito no mundo e guiando sua forma de ação no setting. Assim, a autora assinala a necessidade de o analista buscar, ao longo do tratamento, a criação de possibilidades para a emergência de experiências resultantes do estabelecimento de uma relação intersubjetiva doadora de sentido e produtora de um efeito organizador para a subjetividade do paciente. Diante disso, ressalta a importância de a dimensão sensorial da transferência ser resgatada para uma compreensão mais ampla do campo transferencial.

Safra (2005) é outro autor que frisa a importância do resgate da sensorialidade na relação transferencial. Ele explica que, na clínica com pacientes autistas, que nem mesmo se constituíram, o analista necessita de procedimentos que possibilitem ao sujeito utilizar-se do campo transferencial para constituir aspectos fundamentais de seu self que até então ficaram sem realização. Ao fornecer as funções buscadas pelo paciente para que ele dê continuidade ao desenvolvimento de si mesmo, o analista observa fenômenos de significação e de articulação simbólica. Contudo, Safra esclarece que, mais do que um processo de deciframento das produções do paciente, há uma apresentação do self em gesto e em formas imagéticas (formas sensoriais) sustentadas pela relação transferencial, na qual o indivíduo se constitui 
e se significa frente ao outro.

Em seu trabalho, Safra (2005) demonstra a importância dos vínculos sensoriais não-verbais na transferência. Em suas palavras, é "fundamental que o analista possa acompanhar tanto vivências psíquicas que se expressam pela linguagem discursiva, quanto aquelas que emergem, por meio de símbolos estéticos, como símbolos do self, articulados plasticamente no campo sensorial" (Safra, 2005: 29-30).

Tafuri (2003) ilustra a utilização dos vínculos sensoriais não-verbais na clínica com crianças autistas ao descrever o caso clínico de Maria, no qual um jogo de sons entre a analista e a criança proporciona a constituição de um "ambiente-holdingsonoro", possibilitando o manejo da relação analítica com a criança. A partir desse trabalho de Tafuri, outros trabalhos vêm sendo desenvolvidos no Laboratório de Psicopatologia e Psicanálise do Instituto de Psicologia da Universidade de Brasília, demonstrando a importância dos vínculos sensoriais não-verbais para o manejo da transferência na clínica psicanalítica com crianças autistas. Dentre eles podemos destacar os trabalhos de Benjamin (2007) sobre o ritmo, de Januário (2008) sobre o olhar e de Araújo (2008) sobre o corpo.

\section{CONSIDERAÇÕES FINAIS}

Com relação à história da clínica psicanalítica com crianças autistas, foi constatado que o manejo da relação transferencial era realizado por meio de interpretações verbais. Diante disso, discutiu-se o lugar de analista intérprete, herança clássica kleiniana, no qual o papel da analista é o de interpretar, o mais breve possível, o simbolismo revelado por detalhes do comportamento da criança, mesmo na ausência da fala e do brincar simbólico.

Contudo, a partir das obras de Winnicott, mostrou-se o desenvolvimento de uma abordagem diferente da tradicional que contribui de forma significativa para a clínica psicanalítica com crianças autistas. Dentre as ideias de Winnicott, ressaltaram-se a noção de holding, a relação transferencial para além da interpretação, o modelo da "mãe suficientemente boa" como norteador da transferência e a importância dos vínculos sensoriais não-verbais.

Foi discutido o fato de a clínica com crianças autistas colocar em questão a perspectiva clássica de que a análise de qualquer pessoa pode ser feita por meio da linguagem verbal. Nessa clínica, a técnica clássica da interpretação está, muitas vezes, inabilitada, não sendo possível interpretar os comportamentos das crianças. Assim, o trabalho de análise entra em uma situação de impasse, pois a técnica clássica da interpretação pode ameaçar ainda mais o paciente, levando-o a experiências 
de desintegração e de fragmentação. Diante disso, ressaltou-se a importância dos vínculos sensoriais não-verbais no manejo da transferência.

\section{REFERÊNCIAS}

Abram, J. (1996/2000). A linguagem de Winnicott. Dicionário das palavras e expressóes utilizadas por Donald W. Winnicott. Rio de Janeiro: Revinter.

Araújo, C. F. N. (2008). Acolhe-me em teu colo: a função do corpo do analista no tratamento psicanalítico com a criança autista. Dissertação de Mestrado, Curso de Pós-graduação em Psicologia Clínica e Cultura. Universidade de Brasília, Brasília.

Benjamin, M. S. (2007). Entre rodopios e balbucios: reflexôes psicanalíticas sobre a função do ritmo na constituição psíquica. Dissertação de Mestrado, Curso de Pós-graduação em Psicologia Clínica e Cultura, Universidade de Brasília, Brasília.

Figueiredo, L. C. (2000). Presença, implicação e reserva. In: Figueiredo, L. C. \& Coelho Junior, N. Ética e técnica em psicanálise (pp. 9-50). São Paulo: Escuta.

Furtado, A. M. (2006). O resgate da sensorialidade na transferência. Tese de doutorado, Curso de Pós-graduação em Saúde Coletiva, Universidade do Estado do Rio de Janeiro, Rio de Janeiro.

Januário, L. M. (2008). A transferência na clínica psicanalítica com crianças em sofrimento psíquico grave. Dissertação de Mestrado, Curso de Pós-graduação em Psicologia Clínica e Cultura, Universidade de Brasília, Brasília.

Kanner, L. (1943/1997). Os distúrbios do contato afetivo. In: Rocha, P. (org.). Autismos (pp. 111-170). São Paulo: Escuta.

Klein, M. (1930/1996). A importância da formação dos símbolos no desenvolvimento do ego. In: Amor, culpa e reparação e outros trabalhos (pp. 249-264). Rio de Janeiro: Imago.

Safra, G. (2004). Winnicott: da pediatria à psicanálise (DVD-VÍDEO). Série: A visão clínica de Gilberto. São Paulo: Realização Ediçōes Sobornost.

Safra, G. (2005). A face estética do self: teoria e clínica. São Paulo: Idéias e Letras/ Unimarco Editora.

Tafuri, M. I. (2003). Dos sons à palavra: exploraçôes sobre o tratamento psicanalítico da criança autista. Brasília: Positiva/Abrafipp.

Winnicott, D. W. (1954/2000). Retraimento e regressão. In: Da pediatria à psicanálise: obras escolhidas (pp. 347-354). Rio de Janeiro: Imago.

Winnicott, D. W. (1955a/2000). Aspectos clínicos e metapsicológicos da regressão no 
contexto psicanalítico. In: Da pediatria à psicanálise: obras escolhidas (pp. 374-392). Rio de Janeiro: Imago.

Winnicott, D. W. (1955b/2000). Formas clínicas da transferência. In: Da pediatria à psicanálise: obras escolhidas (pp. 393-398). Rio de Janeiro: Imago.

Winnicott, D. W. (1956/2000). A preocupação materna primária. In: Da pediatria à psicanálise: obras escolhidas (pp. 399-405). Rio de Janeiro: Imago.

Winnicott, D. W. (1962/1983). Dependência no cuidado do lactente, no cuidado da criança e na situação psicanalítica. In: $O$ ambiente e os processos de maturação: estudos sobre a teoria do desenvolvimento emocional (pp. 225-233). Porto Alegre: Artmed.

Winnicott, D. W. (1968/1996). A comunicação entre o bebê e a mãe e entre a mãe e o bebê: convergências e divergências. In: Os bebês e suas mães (pp. 79-92). São Paulo: Martins Fontes.

Winnicott, D. W. (1972/2001). Holding e interpretação. São Paulo: Martins Fontes.

Winnicott, D. W. (1988/1990). Natureza humana. Rio de Janeiro: Imago.

Recebido em 23 de março de 2009 Aceito para publicação em 26 de abril de 2010 